\title{
Biocompatibility of Different Universal Adhesives During Short and Long Periods on Rat Model
}

\author{
Murat ÜNAL ${ }^{1}$, Ayşegül SAYGIN ${ }^{2}$, Tülay KOÇ ${ }^{3}$, Merve CANDAN ${ }^{1}$, İrem \\ IPEK ${ }^{1}$ \\ ${ }^{1}$ Sivas Cumhuriyet University, Faculty of Dentistry, Department of Pediatric Dentistry \\ ${ }^{2}$ Sivas Cumhuriyet University, Faculty of Dentistry, Department of Prosthodontics \\ ${ }^{3}$ Sivas Cumhuriyet University, Faculty of Medicine, Department of Pathology \\ gmuratunal@hotmail.com
}

\begin{abstract}
This in vivo research aimed to compare the biocompatibility of five different Universal adhesives (UAs) in short and long periods. 108 polyethylene tubes filled with five UAs [Group 1: All Bond Universal (ABU), Group 2: Prime Bond Elect Universal (PBU), Group 3: Single Bond Universal (SBU), Group 4: Clearfil Universal Bond Quick (CUB), Group 5: Futurabond U (FBU)] or Group 6: empty (control group)] were implanted into the dorsal connective tissue of 36 rats. Groups 1,2 and 3 were implanted in 18 rats, the other groups Groups 4, 5 and 6 were implanted in 18 rats. Then, the rats were sacrificed after time intervals 7, 30 and 90 days $(n=12)$. Biopsy samples were examined in terms of inflammatory reaction, necrosis, macrophage infiltrate, giant cell and fibrous capsule criteria. When the UAs groups and control group were compared on the 7th, 30th and 90th days, significant statistical differences were found only on the 7th day in terms of fibrous capsule and macrophage infiltrate $(\mathrm{p}<0.05)$. In addition, statistical significant differences were found upon within the control group in terms of inflammation, necrosis, giant cell, fibrous capsule and macrophage infiltrate criteria on the 7th, 30th and 90th days $(p<0.05)$. The all UAs that we used in our study have showed good biocompatibility in the subcutaneous tissues of the rats, and we think that they could be used clinically with resin-based restorative materials in all restorative treatments including deep dentine caries restorations.
\end{abstract}

KEY WORDS: Universal Adhesives, Biocompatibiltity, Rat, Subcutaneous Tissue, Short-Long Period

\section{Introduction}

Biocompatibility is one of the essential features of any dental material (DM). It means that a material applied to living tissue could remain stable without causing any any deterioration in the surrounding tissues $[1,2]$. DM's biocompatibility are a complex issue that includes biological factors, patient risk factors, clinical experiences and engineering issues. It is likely for dentists, dentistry students, physician assistants, patients etc. to receive detriment in the process of applying dental materials [3]. One of the methods used to determine the biocompatibility of DMs is subcutaneous implantation test. Rats, pigs and hamsters are often used in these tests. Although it is a low-cost method, it provides researchers an easier analysis since it is not processed in hard tissues. In this method, while the formable materials are placed directly into the tissue, soft materials that can not be shaped are placed in the subcutaneous dermis area with a stick-shaped test material in tubes such as polyethylene [4, 5]. Universal adhesive (UA) systems are very popular new generation bonding systems, which could be used in 3 different methods as self-etch, total-etch, and selective-etch modes [6]. These adhesives could be attached to different types of biomaterials (ceramic, metal, zirconia, composite, etc.) and can be applied in different modes for any clinical situation [7]. Many of the dental adhesives contain specific carboxylate and/or phosphate monomers 
that can ionically bond to calcium in hydroxyapatite [8]. UAs, also contain aromatic amines, photoinitiators and filler particles. These additional components may alter the biological behavior of the pulp-dentin complex if they are not included in the polymer network. Organic solvents that can be released after polymerization may reach pulp through dentin tubules and cause different degrees of irritation in the pulp [9]. HEMA is the hydrophilic monomer contained in UAs. It augments the infiltration of adhesive resin to dentin tubules, thereby providing a better bond strength to the tooth structures [10]. Camphorquinone (CQ), another component of UA systems is a photoinitiator released after polymerization $[11,12]$. This is not a component of the polymer chain, so some of the components not involved in polymerization can cause oxidative stress, DNA damage and cytotoxicity [12]. During the polymerization process of the resin monomer, double carbon bonds $(\mathrm{C}=\mathrm{C})$ need to transform into a single carbon bond (C-C) to create polymer. If this chemical bond transformation is insufficient and incomplete transformation occurs, the material may cause cytotoxicity in the tissue. Resin based materials often may not polymerize completely when using light. As a result, it has been submitted that there is a significant relationship between leaking, nonpolymerized monomers from resin based materials and their cytotoxic effects [13]. It is known that monomers released from adhesives can negatively affect the cellular function of fibroblasts and can cause direct biological reactions in the pulp tissue [14]. In addition, it is stated in some research that the monomers might cause odontogenic differentiation in stem - non stem pulp cells and delay in mineralization processes $[15,16]$. While cytotoxic effects of dental adhesives have been shown in many in-vitro studies in the literature, the number of in-vivo studies is very limited. Also, when the literature reviewed, it would be seen that there is no in-vivo biocompatibility study related to UAs. As a result, this research is the first in-vivo study to histologically examine the biocompatibilities of different UAs, fibrous capsule, inflammation, necrosis, giant cell formations and macrophage infilrate on the rat model.

The null hypothesis in our study was that 5 different UA systems would differ significantly in terms of biocompatibility at different time intervals.

\section{Experimental}

\subsection{Materials}

This research was approved by the Ethics Commission of Sivas Cumhuriyet University Animal Experiments (2019/217).

A total of 36 Wistar male albino rats, weighing 200-220 gr, were used in the study. All experiments were conducted in compliance with the National Institute of Health' s Guidelines for the Care, Use of Laboratory Animals, in accordance with the 1964 Helsinki declaration and its later amendments or comparable ethical standards. The subjects were kept in standard test cages at $22-24^{\circ} \mathrm{C}, 55-70 \%$ humidity, $1 \mathrm{~atm}$ pressure for 12 hours in a light/dark room and their health status was checked regularly. In present study, five different UAs that would determine each group were used and their contents are shown in Table $1.5 \mathrm{~mm}$ length, $1.5 \mathrm{~mm}$ inner diameter polyurethane [Nontoxic Scalp Vein 19G] tubes(PTs) were disinfected with $96 \%$ alcohol solution before experiment. UAs were placed in PTs prepared in standard sizes under sterile conditions with the help of a bonding brush. A total of 6 PTs for each UA group were polymerized with a LED light device (Elipar ${ }^{\mathrm{TM}} \mathrm{S}$ 10, 3M ESPETM, St. Paul, MN, USA) for 10 seconds from all surfaces. 108 PTs were obtained, filled with 5 different UA and without UA (control) [(Group 1: All-Bond Universal ${ }^{\circledR}$ (AB) (Bisco Inc., USA); Group 2: Prime\&Bond Universal Elect (PB) (Dentsply Caulk, USA); Group 3: Single Bond Universal Adhesive (SB) (3M ESPE, USA); Group 4: Clearfill Universal Bond Quik (CB) (Kuraray NoritakeDental Inc., Japan); Group 5: Futurabond ${ }^{\circledR}$ $\mathrm{U}$ (FB) (Voco GmbH, Germany) and Group 6 (control)]. Groups 1, 2 and 3 were implanted in 18 rats, the other groups Groups 4, 5 and 6 were implanted in 18 rats.

\subsection{Method}

The animals have been anesthetized with ketamine HCL $(25 \mathrm{mg} / \mathrm{kg})$ and xylazine $(10 \mathrm{mg} / \mathrm{kg})$. After shaving the animals dorsal area and cleaning these surface, the regions where the samples would be placed were determined. Areas were created by making totally 3 incisions in the dorsal part of each animal to the skin and subcutaneous region in the determined operation areas which 2 in the shoulder and 1 being in waist regions. The incisions were adjusted to be on either side of the midline and at least $2 \mathrm{~cm}$ apart from each other. After then, subcutaneous pockets of $1 \mathrm{~cm}$ depth were created by blunt dissection in the incision areas, using 
dissecting scissors. PT containing a different UA material was placed in each subcutaneous pocket under aseptic conditions. Subsequently, the incision lines were sutured by silk 3.0 sutures.

After waiting time intervals of 7, 30 and 90 days, 12 rats were euthanized after anesthesia on each time periods. The regions under the skin where PTs placed were detected. The biopsy specimens, together with the PT and sufficient normal surrounding connective tissue, were removed.

All biopsied specimens were kept in sterile storage containers for $24-48$ hours in $10 \%$ buffered formalin solution and fixation process were performed. Xylene was used for deparaffinization of undyed sections and for lamination after staining. Paraffin was used to hardening the tissues. This situation enabled histological examination and obtaining sections from biopsy materials. Microtome device (Thermo 36 Scientific Shandon Finesse 325, China) was used to obtain $5 \mu \mathrm{m}$ thick sections from the paraffinized tissues.
Hematoxylin \& Eosin was used to dye deparaffinized samples. Light microscope (Nikon Eclipse E200, Japan) was used for histological examination of tissue preparations. Light microscope (Nikon Eclipse E400, Japan) with digital camera attachment (Nikon DS-Ri1, Japan) was used to photograph histological images. After the prepared slides were examined under 40, 100 and $200 \mathrm{X}$ magnifications with a light microscope, they were photographed under the light microscope with digital camera attachment. The tissue samples were quantitatively evaluated by a pathologist (T.K) using the scoring shown in Table 2 for the criteria of inflammation, fibrous capsule, necrosis, giant cell and macrophage infiltrate.

Table 1. Five different UAs and their composition

\begin{tabular}{|c|c|c|c|}
\hline $\begin{array}{l}\text { Materials/Lot } \\
\text { number }\end{array}$ & $\mathrm{pH}$ & Manufacturer & Composition \\
\hline $\begin{array}{l}\text { Clearfil Universal } \\
\text { Bond } \quad \text { Quick } \\
(000010)\end{array}$ & 2.3 & $\begin{array}{l}\text { Kuraray, } \\
\text { Okayama, } \\
\text { Japan }\end{array}$ & $\begin{array}{l}\text { 10-MDP, Bis-GMA, HEMA, Hydrophilic amide monomer, } \\
\text { Colloidal silica, Ethanol, dl-Camphorquinone, Accelerators, } \\
\text { Water, Sodium fluoride }\end{array}$ \\
\hline $\begin{array}{l}\text { Single } \\
\text { Universal } \\
(70818 C)\end{array}$ & 2.7 & $\begin{array}{l}3 \mathrm{M} \text { ESPE St. } \\
\text { Paul, } \text { MN USA }\end{array}$ & $\begin{array}{l}\text { 10-MDP phosphate monomer, Vitrebond copolymer, HEMA, } \\
\text { dimethacrylate resins, filler, silane, initiators, ethanol, water }\end{array}$ \\
\hline $\begin{array}{l}\text { All Bond } \\
\text { Universal } \\
(1700005470)\end{array}$ & 3.2 & $\begin{array}{l}\text { Bisco, } \\
\text { Schaumburg, IL } \\
\text { USA }\end{array}$ & $\begin{array}{l}\text { 10-MDP phosphate monomer, Bis-GMA, HEMA, water, } \\
\text { ethanol, photoinitiator }\end{array}$ \\
\hline $\begin{array}{l}\text { Prime Bond Elect } \\
\text { Universal } \\
(1703000839)\end{array}$ & 2.5 & $\begin{array}{l}\text { Dentsply, Caulk, } \\
\text { USA }\end{array}$ & $\begin{array}{l}\text { Mono-, di- and trimethacrylate resins, PENTA, diketone, } \\
\text { stabilisersorganic phosphine oxide, cetylaminehydrofluoride, } \\
\text { acetone, water, self-cure activator }\end{array}$ \\
\hline $\begin{array}{l}\text { Futura bond } U \\
(18077614)\end{array}$ & 2.3 & Voco, Germany & $\begin{array}{l}2 \text { HEMA Bis-GMA HEMA, acidic adhesive monomer, } \\
\text { urethane dimethacrylate, catalyst, silica, nanoparticles, ethanol }\end{array}$ \\
\hline
\end{tabular}

Table 2. Histological criteria and scores

\begin{tabular}{|c|c|c|c|c|}
\hline \multirow{2}{*}{ Criteria } & \multicolumn{4}{|c|}{ Scores } \\
\cline { 2 - 5 } & 0 & 1 & 2 & 3 \\
\hline İnflammation & $\begin{array}{c}\text { No detected } \\
\text { inflammatory cells }\end{array}$ & $\begin{array}{c}\text { Less than } 25 \text { cells } \\
(\text { mild })\end{array}$ & $\begin{array}{c}\text { Between } 25 \text { and } \\
125 \text { cells } \\
\text { (moderate) }\end{array}$ & $\begin{array}{c}125 \text { or more cells } \\
\text { (severe) }\end{array}$ \\
\hline Fibrous Capsule & Absent & Thin,$\leq 150 \mu \mathrm{m}$ & Thick $\geq 150 \mu \mathrm{m}$ & \\
\hline Macrophage Infiltrate & $<10$ cells & $\geq 10$ to 20 cells & $\geq 20$ to 30 cells & $>30$ cells \\
\hline Necrosis & Absent & Present & & \\
\hline Giant Cells & Absent & Present & \\
\hline
\end{tabular}




\subsection{Statistical Analysis}

The data obtained in present study were analyzed in the SPSS 22.0 software. Kruskal-Wallis test was used in the evaluation of the data, in which the datas obtained from more than two independent groups were compared, as the parametric test assumptions were not met. In addition, Mann-Whitney U test was used to find groups that made a difference. Friedman test was used to compare the datas obtained at different times and Wilcoxon test was used to find the difference between the groups. $\mathrm{P}<$ 0.05 value was accepted as statistically significant.

\section{Results and discussion}

All statistical results of this study are shown in the Table 3. Analysis of data from UAs and the control groups in terms of inflammation, fibrous capsule, necrosis, giant cell and macrophage infiltrate criteria on the 7 th, 30th and 90th days has indicated the following results (Figure 1): When the 7th day inflammation scores of the UA groups were compared, the difference between the groups was found to be significant $(p<0.05)$. When the values for the groups were compared in pairs, the difference between the single bond-control and prime bond-control was found to be significant ( $\mathrm{p}$ $<0.05$ ), while the difference between the other groups was found to be insignificant ( $p>0.05$ ). When the 30th day inflammation scores of the UA groups were compared, the difference between the groups was found to be significant $(\mathrm{p}<0.05)$. When the values for the groups were compared in pairs, the difference between the single bond-control was found to be significant $(\mathrm{p}<0.05)$, while the difference between the other groups was found to be insignificant $(p>0.05)$. When the 90th day inflammation scores of the UA groups were compared, the difference between the groups was found to be significant $(p<0.05)$. When the values for the groups were compared in pairs, the difference between the single bond-clearfill bond, single bond-control, clearfill bond-prime bond, clearfill bond-futura bond, prime bond-control and futura bond-control was found to be significant (p $<0.05$ ), while the difference between the other groups was found to be insignificant $(\mathrm{p}>0.05)$. When the 90th day inflammation scores of the UA groups were compared, the difference between the groups was found to be significant $(\mathrm{p}<0.05)$. When the values for the groups were compared in pairs, the difference between the single bond-clearfill bond, single bond-control, clearfill bond-prime bond, clearfill bond-futura bond, prime bond- control and futura bond-control was found to be significant $(\mathrm{p}<0.05)$, while the difference between the other groups was found to be insignificant $(\mathrm{p}>$ $0.05)$. There were significant differences in $A B$ 's giant cell and macrophage infiltrate criteria ( $\mathrm{p}$ $<0.05$ ), while there was no significant difference in terms of fibrous capsule, giant cell and necrosis ( $p>$ 0.05 ). There were significant differences in giant cell, macrophage infiltrate and inflammation criteria $(\mathrm{p}<0.05)$ in $P B, C B$ and $F B$ groups, while the difference was not significant in terms of fibrous capsule and necrosis ( $p>0.05)$. There were significant differences in giant cell, macrophage infiltrate, fibrous capsule and inflammation criteria $(\mathrm{p}<0.05)$ in the $S B$ group, while the difference was not significant in terms of necrosis $(p>0.05)$. There were significant differences $(p<0.05)$ in the all five histological evaluation criteria in control group. ${ }^{* *}$ Between group comparisons in terms of criteria and time have yield these results: The intergroup difference was significant on the 7 th day $(p<0.05)$ in terms of macrophage infiltrate and fibrous capsule criteria, while there was no significant difference on the 30th and 90th days ( $p>0.05)$. The intergroup difference was insignificant on the 7 th, 30th and 90th days ( $p>0.05)$ in terms of giant cell, inflammation and necrosis criteria. According to the results of our study, it has been observed that the biocompatibility of 5 different universal adhesives changes over time. Therefore, the null hypothesis was accepted. Although several studies have been carried out to evaluate the biological properties of many materials used in dentistry, the number of studies on universal adhesives are quite limited in the literature $[5,9,11,15,16]$. Under the light of this fact, we clinically analyzed the biocompatibility of UAs that facilitate application in three different ways. Experimental animals are frequently used in biocompatibility research to evaluate the tissue response of the DMs and provide crucial information about the biocompatibility of materials. In dentistry, animal studies are carried out to develop surgical techniques or identify the effects of DMs on the living tissues and these researches play a very important role in determining their effectiveness and reliability of these materials. It has been stated that local inflammation and toxicities could be determined through the implantation of DMs into the subcutaneous connective tissue in experimental animals. Since the resulting inflammatory tissue response is similar to that of exposed pulp and connective tissue, subcutaneous implantation tests are considered as a reliable 
method for assessing the biocompatibility of DMs [17]. It is known that subcutaneous implantation tests generally consider day 7,30 and 90 as experimental periods.

Fig. 1. Histopathological section samples belonging to all groups.

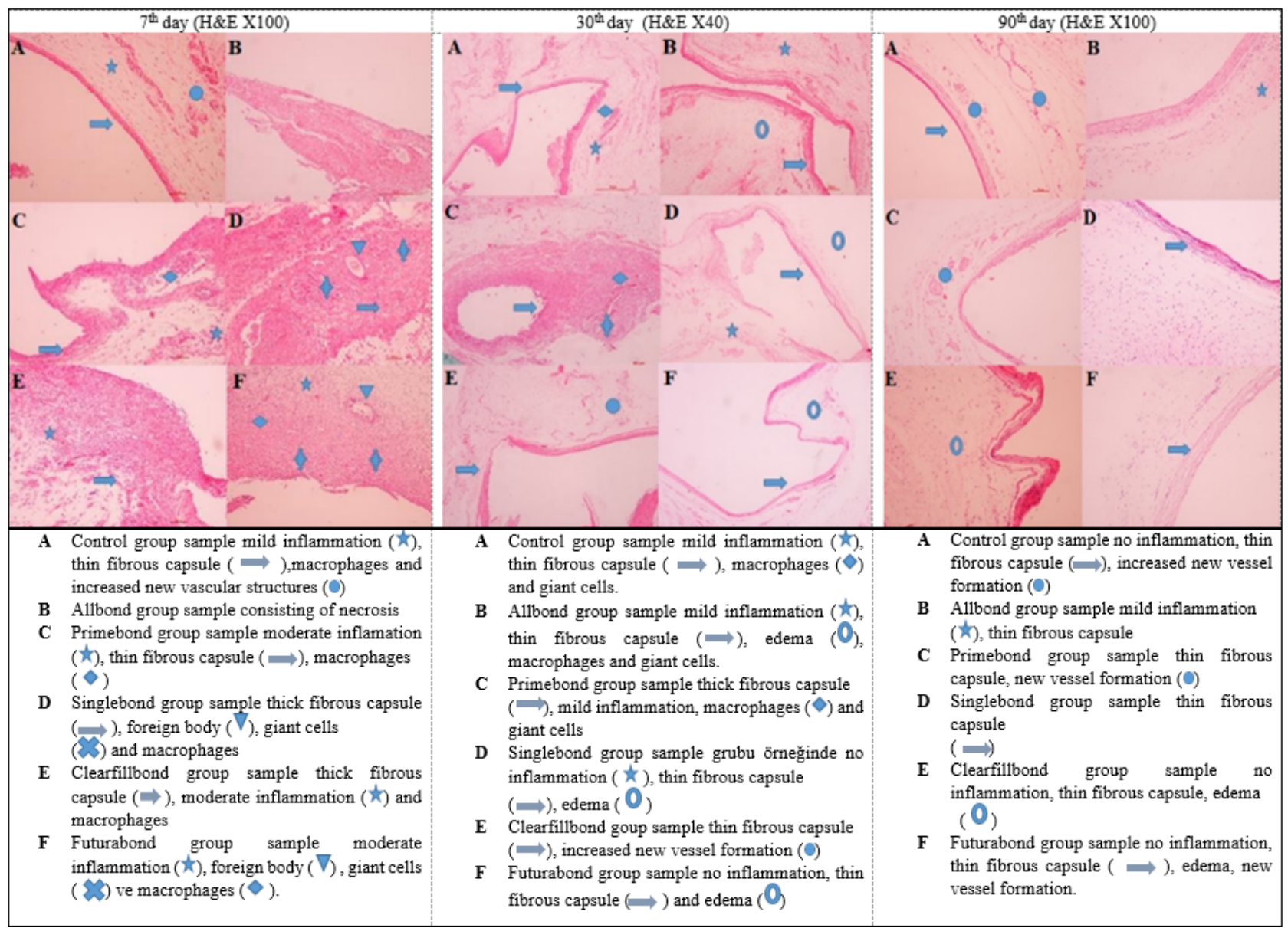

Following these periods, the test material excised with some intact tissue around it is examined histologically. In the examination, the duration and severity of the inflammatory response is the basis $[18,19]$. In line with these thoughts, as time intervals in our study; we examined histological changes in tissues at 7, 30 and 90 days parameters. In biocompatibility studies, the tissue' s response to the material is evaluated between the $2 \mathrm{nd}$ and 12 th weeks. In both processes, if there is no reaction or it is moderate, the material is confirmed to pass the test. If the reaction started at week 2 decreases at week 12 , the material is still confirmed to pass the test. However, the samples showing moderate reactions in both periods are considered to fail the test. Although there is no reaction or moderate reaction at week 2 , it is considered that the material fails the test if it is moderate or severe at the end of week 12 [17]. Based on these criteria, it can be said that all the universal adhesives have passed the biocompatibility test when the results of our study are examined. Costa et al. [20] evaluated the biocompatibility of two different dental adhesives and calcium hydroxide in the subcutaneous tissues of the rats on the 7th, 30th and 60th days. At the end of the 7th day, a moderate inflammatory response detected in both adhesives. At the end of the 30th day, fibrous capsules surrounding the tubes were observed. After 60 days, they found a continuous inflammatory reaction mediated by macrophage and giant cells in most of the samples, as well as connective tissue healing. In present research, the inflammation was high on the 7 th day and decreased in 30 days. 
The inflammation continued to decrease towards the 90th day. In addition, due to the decrease in inflammation over time, the thickness of the fibrous capsule, macrophage infiltrate and giant cell decreased. Santos et al. [21] evaluated the biocompatibility of 4 different orthodontic adhesives in rat subcutaneous tissue, argued that the severe inflammation that occurred on the 7 th day was not caused by the applied material but by the trauma caused by the surgical procedure. In addition, all orthodontic adhesives were found to have good biocompatibility at the end of the 30th day. Teixeira et al. [22] evaluated the biocompatibility of three different adhesives and calcium hydroxide on the 15th, 30th and 60th days, a moderate-intensive. inflammatory reaction was observed at the end of the 15th day. It was reported that the inflammatory response decreased over time and there was no inflammatory response to calcium hydroxide at the end of the 30th day, and a thin capsule formation. At the end of the 60th day, it determined that an ongoing inflammatory reaction to the dental adhesives developed. In our study, a moderate inflammatory reaction was observed on the 7th day and a low inflammatory reaction at the end of the 30th day in all the UA's. On the 90th day, the low inflammation continued.
In addition, fibrous capsule thickness, macrophage infiltration and giant cell decreased from 7 th day to 90th day. In addition to in-vivo studies mentioned above, in vitro cytotoxicity studies, which included some universal adhesive systems, are described below. In an in-vitro study by Yildirım et al. [23] the cytotoxicity of 5 different adhesives was compared at the 24th, 48th and 72nd hours in the cell culture medium. It is stated that the cytotoxic effect of all adhesives increases depending on the dose and varied over time. In our study, the inflammation of all UAs used changed and decreased over time Necrosis is defined as the uncontrolled death of the cell and is associated with the increase of the resulting lifeless cells and the release of increased inflammatory cytokines. It was seen only in one sample on the 7th day in the Allbond, Single bond and Clearfil groups, which are among the universal adhesives in our study. No necrosis was observed in any group on the 30th and 90th days Futura universal adhesive used in our study contains UDMA, unlike the other 4 universal adhesive materials. In their study, Szep et al [24], suggested that materials containing the BisGMA + UDMA + HEMA will be more toxic than materials containing BisGMA + HEMA. When the results of our study are examined, it is seen that they are similar to the results of the study by Szep et al.

Table 3. Evaluation results for all UAs groups, on day 7 th, 30th and 90th

\begin{tabular}{|c|c|c|c|c|c|c|c|c|c|c|c|c|c|c|}
\hline \multirow[b]{2}{*}{ Parameters } & \multirow[b]{2}{*}{ Time } & \multicolumn{2}{|c|}{ All bond } & \multicolumn{2}{|c|}{ Prime bond } & \multicolumn{2}{|c|}{ Single bond } & \multicolumn{2}{|c|}{ Clearfill bond } & \multicolumn{2}{|c|}{ Futura bond } & \multicolumn{2}{|c|}{ Control } & \multirow[b]{2}{*}{$p$-value } \\
\hline & & Mean & $\underset{(\text { med) }}{\text { Min-Max }}$ & Mean & $\begin{array}{l}\text { Min- } \\
\text { Max } \\
\text { (med) }\end{array}$ & Mean & $\begin{array}{l}\text { Min- } \\
\text { Max } \\
\text { (med) }\end{array}$ & Mean & $\underset{(\text { med) }}{\text { Min-Max }}$ & Mean & $\begin{array}{l}\text { Min- } \\
\text { Max } \\
\text { (med) }\end{array}$ & Mean & $\begin{array}{l}\text { Min- } \\
\text { Max } \\
\text { (med) }\end{array}$ & \\
\hline \multirow{4}{*}{ Inflammation } & $7^{\text {th }}$ day & $2,00^{2, b}$ & $1-3(2)$ & $2,33^{\mathrm{A}}$ & $1-3(2)$ & $2,5^{\mathrm{B}, \mathrm{a}}$ & $1-3(3)$ & $2,00^{2}$ & $1-3(2)$ & $1,67^{a}$ & $1-2(2)$ & $1,00^{4, B}$ & $1-1(1)$ & $0,021^{*}$ \\
\hline & 30th day & $1,33^{a c}$ & $1-2(1)$ & $1,00^{4}$ & $0-2(1)$ & $1,67^{\AA}$ & $1-2(2)$ & $1,33^{\mathrm{b}}$ & $1-2(1)$ & $1,00^{\mathrm{b}}$ & 1-1(1) & $0,50^{\mathrm{Ana}}$ & $\begin{array}{c}0- \\
1(0,5)\end{array}$ & $0,020^{*}$ \\
\hline & 90th day & $0,67^{\mathrm{hec}}$ & $0-1(1)$ & $0,83^{\mathrm{A}, \mathrm{B}, \mathrm{a}}$ & $0-1(1)$ & $0,83^{C, D, 2}$ & $0-1(1)$ & $0,17^{\mathrm{B}, \mathrm{CF}, \mathrm{b}, \mathrm{b}}$ & $0-1(0)$ & $0,83^{E, F, a, b}$ & $0-1(1)$ & $0,17^{A, D, F, A}$ & $0-1(0)$ & $0,023^{*}$ \\
\hline & $\mathrm{p}$-value & $0,011^{*}$ & & $0,015^{*}$ & & $0,011^{*}$ & & $0,004^{*}$ & & $0,015^{*}$ & & $0,022^{*}$ & & \\
\hline \multirow{4}{*}{$\begin{array}{l}\text { Fibrous } \\
\text { capsule }\end{array}$} & 7 th day & 1,5 & $1-2(1,5)$ & 1,33 & $1-2(1)$ & $1,83^{\mathrm{Aa}}$ & $1-2(2)$ & $1,83^{\mathrm{B}}$ & $1-2(2)$ & 1,5 & $\begin{array}{c}1- \\
2(1,5)\end{array}$ & $1^{A, B}$ & $1-1(1)$ & $0,040^{*}$ \\
\hline & 30th day & 1,33 & $1-2(1)$ & 1,16 & $1-2(1)$ & 1,16 & $1-2(1)$ & 1,5 & $1-2(1,5)$ & 1,16 & $1-2(1)$ & $1,6^{\mathrm{a}}$ & $1-2(2)$ & 0,323 \\
\hline & 90th day & 0,83 & $0-1(1)$ & 1,16 & $1-2(1)$ & $1^{\mathrm{a}}$ & $0-2(1)$ & 1,16 & $1-2(1)$ & 1 & 1-1(1) & $0,66^{a}$ & $0-1(1)$ & 0,332 \\
\hline & $\mathrm{p}$-value & 0,074 & & 0,717 & & $0,023^{*}$ & & 0,135 & & 0,097 & & $0,015^{*}$ & & \\
\hline \multirow{4}{*}{ Necrosis } & 7 th day & 0,16 & $0-1(0)$ & 0,33 & $0-1(0)$ & 0,16 & $0-1(0)$ & 0,16 & $0-1(0)$ & 0 & $0-0(0)$ & $0,6^{6^{2, b}}$ & $0-1(1)$ & 0,145 \\
\hline & 30th day & 0 & $0-0(0)$ & 0 & $0-0(0)$ & 0 & $0-0(0)$ & 0 & $0-0(0)$ & 0 & $0-0(0)$ & $0^{a}$ & $0-0(0)$ & \\
\hline & 90th day & 0 & $0-0(0)$ & 0 & $0-0(0)$ & 0 & $0-0(0)$ & 0 & $0-0(0)$ & 0 & $0-0(0)$ & $0^{b}$ & $0-0(0)$ & \\
\hline & $\mathrm{p}$-value & 0,368 & & 0,135 & & 0,368 & & 0,368 & & & & $0,018^{*}$ & & \\
\hline \multirow{4}{*}{ Giant cell } & 7th day & $0,83^{2}$ & $0-1(1)$ & $1^{\text {ab }}$ & $1-1(1)$ & $0,83^{a, b}$ & $0-1(1)$ & $0,83^{2}$ & $0-1(1)$ & $1^{ \pm}$ & 1-1(1) & $0,83^{a}$ & $0-1(1)$ & 0,821 \\
\hline & 30th day & 0,5 & $0-1(0,5)$ & $0,33^{a}$ & $0-1(0)$ & $0^{\mathrm{a}}$ & $0-0(0)$ & 0,5 & $0-1(0,5)$ & 0,5 & $\begin{array}{c}0- \\
1(0,5)\end{array}$ & 0,5 & $\begin{array}{c}0- \\
1(0,5)\end{array}$ & 0,416 \\
\hline & 90th day & $0,16^{2}$ & $0-1(0)$ & $0,33^{\mathrm{b}}$ & $0-1(0)$ & $0^{b}$ & $0-0(0)$ & $0^{a}$ & $0-0(0)$ & $0,16^{4}$ & $0-1(0)$ & $0^{a}$ & $0-0(0)$ & 0,361 \\
\hline & $\mathrm{p}$-value & $0,047^{8}$ & & $0,041^{*}$ & & $0,007^{*}$ & & $0,022^{*}$ & & $0,004^{*}$ & & $0,042^{*}$ & & \\
\hline \multirow{4}{*}{$\begin{array}{l}\text { Macrophage } \\
\text { Infiltrate }\end{array}$} & 7th day & $1,5^{2 \mathrm{~b}}$ & $0-3(1,5)$ & $1,83^{\mathrm{A}, \mathrm{B}, \mathrm{ab}}$ & $1-3(2)$ & $2,16^{-\mathrm{hb}}$ & $\begin{array}{c}1- \\
3(2,5)\end{array}$ & $1,16^{2, b}$ & $0-3(2)$ & $2,83^{A, C, a b}$ & $2-3(3)$ & $0,83^{\mathrm{BCa}}$ & $0-1(1)$ & $0,048^{*}$ \\
\hline & 30th day & $0,5^{2}$ & $0-1(0,5)$ & $0,16^{a}$ & $0-1(0)$ & $0^{a}$ & $0-0(0)$ & $0,16^{2}$ & $0-1(0)$ & $0,5^{a}$ & $\begin{array}{c}0- \\
1(0,5)\end{array}$ & 0,33 & $0-1(0)$ & 0,314 \\
\hline & 90th day & $0^{b}$ & $0-0(0)$ & $0^{b}$ & $0-0(0)$ & $0^{b}$ & $0-0(0)$ & $0^{\mathrm{b}}$ & $0-0(0)$ & $0^{b}$ & $0-0(0)$ & $0^{a}$ & $0-0(0)$ & \\
\hline & p-value & $0,030^{*}$ & & $0,003^{*}$ & & $0,002^{*}$ & & $0,023^{*}$ & & $0,011^{*}$ & & $0,042^{*}$ & & \\
\hline
\end{tabular}




\section{Conclusions}

With in the limitation of this animal designed study, different UA systems was not differ significantly in terms of biocompatibility at different time intervals. While the tissue response they formed in the tissue is observed in the short term (7th day), in the long term (90th day) it is almost negligible. As a result, UAs could be applied safely in dentistry applications.

\section{Acknowledgment}

We would like to thank Dr. Ziynet Çınar for supporting in the evaluation of the statistical data and to the Serkan Çelikgün for the histology staining. Authors declare that they have no direct or indirect financial interests related to this study.

\section{References}

1. C. A. de Souza Costa, J. Hebling, D. L. Scheffel, D. G. Soares, F. G. Basso, and A. P. D. Ribeiro, Dental Materials, 30 (2014) 769.

2. P. E. Murray, C. G. Godoy, and F. G. Godoy, Medicina Oral, Patología Oral y Cirugía Bucal (Internet), 12 (2007) 258.

3. B. Habib, J. A. Von Fraunhofer, and CF. Driscoll, Journal of Prosthodontics: Implant, Esthetic and Reconstructive Dentistry, 14 (2005) 164.

4. M. Goldberg, Clinical oral investigations, 12 (2008) 1.

5. H. Schweikl, G. Spagnuolo, and G. Schmalz, Journal of Dental Research, 85 (2006) 870.

6. T. Cengiz, M. Unal, Microscopy and Research Technique, 82 (2019) 1032.

7. G. Marchesi, A. Frassetto, A. Mazzoni, F. Apolonio, M. Diolosa, M. Cadenaro, R. Di Lenarda, D. H. Pashley, F. Tay, and L. Breschi, Journal of Dentistry, 42 (2014) 603.

8. K. Yoshihara, Y. Yoshida, N. Nagaoka, S. Hayakawa, T. Okihara, J. De Munck, Y. Maruo, G. Nishigawa, S. Minagi, and A. Osaka, Dental Materials, 29 (2013) 888.

9. S. T. Elias, A. Fd. Santos, F. C. Garcia, P. N. Pereira, L. A. Hilgert, Y. M. Fonseca-Bazzo, E. N. Guerra, and A. P. D. Ribeiro, Brazilian Dental Journal, 26 (2015) 160.

10. J. Perdigão, M. A. Muñoz, A. Sezinando, I. V. Luque-Martinez, R. Staichak, A. Reis, and A. D. Loguercio, Operative Dentistry, 39 (2014) 489.
11. N. J. Lin, L. O. Bailey, M. L. Becker, N. R. Washburn, and L. A. Henderson, Acta Biomaterialia, 3 (2007) 163.

12. J. Volk, C. Ziemann, G. Leyhausen, and W. Geurtsen, Dental Materials, 25 (2009) 1556.

13. R. Şişman, A. Aksoy, M. Yalçın, and E. Karaöz, Journal of Oral Science, 58 (2016) 299.

14. P. Murray, A. Smith, F. G. Godoy, and P. Lumley, International Endodontic Journal, 41 (2008) 389.

15. A. Bakopoulou, G. Leyhausen, J. Volk, P. Koidis, and W. Geurtsen, Dental Materials, 28 (2012) 327.

16. A. Bakopoulou, G. Leyhausen, J. Volk, A. Tsiftsoglou, P. Garefis, P. Koidis, and W. Geurtsen, Dental Materials, 27 (2011) 608.

17. N. S. Sönmez, E. Sönmez, and C. Akçaboy, Indian Journal of Dental Research, 21 (2010) 537.

18. V. Janke, N. Von Neuhoff, B. Schlegelberger, G. Leyhausen, and W. Geurtsen, Journal of Dental Research, 82 (2003) 814.

19. S. Tanchev, P. Georgiev, S. Georgieva, and S. Dimitrov, Bulgarian Journal of Veterinary Medicine, 7 (2004) 77.

20. C. A. de Souza Costa, H. M.Teixeira, A. B. L. do Nascimento, and J. Hebling, Journal of Endodontics, 26 (2000) 512.

21. R. L. d. Santos, M. M. Pithon, A. B. N. Fernandes, M. G. Cabral, and A. C. d. O. Ruellas, Journal of Applied Oral Science, 18 (2010) 498.

22. H. Teixeira, A. Do Nascimento, J. Hebling, and C. De Souza Costa, Journal of Oral Rehabilitation, 33 (2006) 542.

23. Z. S. Yıldırım, Ş. Bakır, E. Bakır and E. Foto, Oral Health \& Preventive Dentistry, 16 (2018) 525.

24. S. Szep, A. Kunkel, K. Ronge, and D. Heidemann, Journal of Biomedical Materials Research: An Official Journal of The Society for Biomaterials, The Japanese Society for Biomaterials, and The Australian Society for Biomaterials and the Korean Society for Biomaterials, 63 (2002) 53. 